\title{
Searching for the Roots of Overprotective Parenting in Emerging Adulthood: Investigating the Link with Parental Attachment Representations Using An Actor Partner Interdependence Model (APIM)
}

\author{
Katrijn, M. Brenning $\bigoplus^{1} \cdot$ Bart Soenens $^{1} \cdot$ Stijn Van Petegem ${ }^{2} \cdot$ Evie Kins $^{1}$
}

(C) Springer Science+Business Media New York 2017

\begin{abstract}
The present study aims to examine why parents engage in overprotective parenting in interaction with their emerging adults. Specifically, this study used an ActorPartner Interdependence Model to examine associations between parental attachment representations (both maternal and paternal attachment anxiety and avoidance), parental separation anxiety, and parental overprotection. Additionally, we examined whether maternal attachment, separation anxiety, and overprotection predicted the emerging adult's actual living situation (at home / away from home) 1 year later, and maternal negative affect regarding emerging adults' home-leaving. The sample consisted of Caucasian participants and included 246 adolescents in their final year of secondary school (mean age Time $1=17.14$ ) and their parents (242 mothers, 218 fathers). Results showed that both maternal and paternal attachment anxiety related to more maternal and paternal separation anxiety, respectively $(p$ 's $<.001)$. In turn, separation anxiety in mothers and fathers related to respectively maternal $(p<.001)$ and paternal overprotection $(p<.05)$, as perceived by the emerging adult. There was one significant partner-effect between maternal attachment anxiety and paternal separation anxiety $(p<.05)$. Further, higher scores on perceived maternal overprotection related to a higher likelihood that the emerging adult would still live at home 1 year later $(p$ $<.01)$, as well as to more negative maternal affect related to the process of home-leaving $(p<.05)$. In sum, the current study revealed the importance of attachment and separation
\end{abstract}

Katrijn, M. Brenning

Katrijn.Brenning@Ugent.be

1 Ghent University, Ghent, Belgium

2 University of Lausanne, Lausanne, Switzerland anxiety as significant parental factors related to parental overprotection.

Keywords Attachment - Separation Anxiety •

Overprotection $\cdot$ Emerging adulthood $\cdot$ Home-leaving

\section{Introduction}

Overprotection involves a level of maternal or paternal protection that is excessive, taking into account the developmental level of the child (Thomasgard et al. 1995). Although for a long time parental overprotection has only been studied at younger ages or in case of psychological or physical disability (Holmbeck et al. 2002; Parker 1983), societal changes (e.g., delayed onset of adulthood) have instigated an interest in studying overprotection in other developmental phases (e.g., emerging adulthood) and in the general population (Padilla-Walker and Nelson 2012). While there is mounting evidence on the potential negative effects of overprotection on children's, adolescents', and even emerging adults' psychosocial adjustment (for an overview, see Segrin et al. 2015), the reasons why parents display such overprotective behavior are not yet widely understood. One previously conducted study among young mothers (Cooklin et al. 2013) identified parental separation anxiety as a predictor of overprotective parenting. As studies on the etiology of maternal separation anxiety have pointed to the influence of mother's own insecure attachment style (Lutz and Hock 1995; Mayseless and Scher 2000; Scher and Hershkovitz 1998), the main aim of the current study was to examine associations between parents' own attachment representations, parental separation anxiety and parental overprotection. Further, a growing body of 
research stresses the possibility of carry-over effects between parents, with characteristics of one parent affecting the behavior of the other parent (see e.g., Peterson et al. 2008). Therefore, the present study used an Actor Partner Interdependence Model (APIM; Kenny et al. 2006) which allowed us to estimate both actor-effects (e.g., effects of maternal attachment on maternal separation anxiety) as well as partner-effects (e.g., effects of maternal attachment on paternal separation anxiety).

Emerging adulthood is the developmental period between the ages of 18 to 25 years (Arnett 1998, 2001). During this phase, people would feel like they are neither adolescents nor adults, but something "in between". Strong dependency on the parents seems to belong to the past, but at the same time emerging adults would not yet carry all responsibilities of adults. Emerging adulthood would be a time of exploration centered on different aspects of life such as love, study, work, and worldview (Arnett 1998). Different developmental tasks would come to the forefront during this phase of life, such as choice of study, adjustment to college and reorganization of the living situation (Arnett 2004). To deal with these and other important developmental tasks, the presence or absence of several personal resources would be crucial, such as agency and flexible commitment (Schwartz et al. 2005), as well as a number of contextual resources, such as a supportive parenting context (Kins et al. 2011; Koepke and Denissen 2012; Schwartz 2016).

In this regard, parental overprotection may play an important role, as it involves the application of developmentally inappropriate parenting tactics that exceed the actual needs of the adolescents and emerging adults (Segrin et al. 2015), and thereby may limit opportunities to practice important skills and abilities (Padilla-Walker and Nelson 2012). Overprotection manifests in various practices, including anxious rearing (e.g., constantly warning for things that could happen), premature problem solving (e.g., intervening in the child's conflicts with others), babying (e.g., telling that the child is too young to do things that peers are allowed to do), privacy invasion (e.g., reading messages on the child's phone) or hyperactivation of emotions (e.g., being more emotional about the child's issues than the child itself) (Kins and Soenens 2013). Previous research already showed that overprotective parenting relates to negative outcomes in emerging adulthood (Rousseau and Scharf 2015; Segrin et al. 2015). For instance, overprotection has been linked with more psychological distress in emerging adults (e.g., depression, anxiety, and stress), as well as with lower life satisfaction and less self-acceptance (e.g., LeMoyne and Buchanan 2011; Segrin et al. 2013). However, studies investigating why parents engage in such overprotective behaviors are scarce. One potentially important parental factor that may relate to parental overprotection is parents' own attachment representations.

Not only for the emerging adults themselves but also for the parents, the transition from adolescence to emerging adulthood heralds a new phase of life, which is sometimes called the empty nest phase (Bouchard 2014). Young adults increasingly interact with others outside the family, which may trigger ambivalent parental emotions (Bouchard 2014). On the one hand, it may seem as if emerging adults no longer need their parents, so parents may feel as if their role as "parent" is over. This feeling can be accompanied by a feeling of loneliness and loss (Hock et al. 2001). On the other hand, parents may feel relieved as well. The responsibilities regarding their children decrease, which may leave them with more time to invest in their partner relationship (Umberson et al. 2005). Research indeed found that, after their child's home-leaving, parents often experience less work-life conflict and less stress (e.g., Erickson et al. 2010). These seemingly contradictory experiences (i.e., loss and relief) may be understood from the perspective of attachment theory (Bowlby 1973, 1980), which states that every departure of an attachment figure may activate the attachment system and the associated attachment representations from the past (Shaver and Mikulincer 2002). Depending on whether these past representations are secure or insecure, people will focus either on the positive or negative features of their role transition. Indeed, according to Hock et al. (2001), the imminent leave-taking of an adolescent child may, for some parents, come across as a threat that activates insecure attachment representations. Hence, when facing a new separation experience, negative feelings may be triggered among insecurely attached parents (Hock et al. 2001).

To model insecure attachment, two fundamental and qualitatively different continuous dimensions (i.e., anxiety and avoidance) have been forwarded (Brennan et al. 1998; Fraley and Spieker 2003). Attachment anxiety involves preoccupation with social support, jealousy, and fear and vigilance concerning abandonment and rejection. Attachment avoidance involves avoidance of intimacy, discomfort with closeness, and excessive self-reliance (Brennan et al. 1998). With regard to overprotective parenting, attachment anxiety is expected to be primarily important (Parker 1983). When facing the imminent home-leaving of their adolescent child, anxiously attached parents might engage in overprotective behaviors as one way to deal with this perceived threat. Although research explicitly examining the link between parental attachment and overprotection is scarce, there are studies among parents of young school children showing that maternal insecure attachment (two-way classification: secure vs. insecure) is related to the use of autonomy-suppressing parenting (i.e., psychological control) (Verschueren et al. 2006). Similarly, research among mothers of 1-2 year old infants found that anxiously 
attached mothers use more intrusive parenting than mothers with secure attachment representations (Adam et al. 2004). However, research investigating the link between parental attachment and overprotection in emerging adulthood is, as far as we know, non-existent.

Further, based on previous research (e.g., Cooklin et al. 2013), separation anxiety can be considered as a potentially intervening variable in the association between parental attachment and parental overprotection. Hock et al. (2001) defined parental separation anxiety as the feeling of apprehension and loss, accompanying the increasing distance between parents and their (adolescent) child. Separation anxiety is a direct manifestation of parental attachment anxiety, specifically in the parent-child relationship (Hock et al. 2001; Kobak et al. 1994). Indeed, previous research on the link between parental attachment and parental separation anxiety in emerging adulthood showed that anxiously attached parents report more separation anxiety whereas parents with secure attachment representations have a more positive attitude towards the separation from their adolescent child (Garcia-Ruiz et al. 2013). For parents of emerging adults, the child's development towards more independence may be experienced as a threat to the parent-child relationship and as a personal rejection, rather than as a normal process (Simpson et al. 1996). The stress associated with the thought of losing their child to others may cause jealousy and possessivenesspossibly even to the extent that these parents will hinder their child's need for autonomy (Hock et al. 2001). Parental feelings of separation anxiety may stimulate an instinctive tendency to provide protection and to increase physical proximity to the child (Bartle-Haring et al. 2002). As such, separation anxiety can result in a compensatory style to undo the separation (which can manifest in overprotection). A number of studies indirectly supported this hypothesis. For example, several studies have shown that parents who interpret the growing independence of their young adult child as a signal of losing this relationship (i.e., high separation anxiety), show more possessive, guilt-inducting and conditional parenting behaviors (i.e., psychological control) to ensure the close proximity and interdependence of their child (see Kins et al. 2011; Soenens et al. 2006; Soenens et al. 2010; Wuyts et al. 2017). Similarly, one study, which focused on mother-infant dyads, found that maternal postpartum separation anxiety during the child's first year of life was associated with more overprotective parenting at age 2-3 years (Cooklin et al. 2013). To the best of our knowledge, no studies are available focusing specifically on emerging adults, let alone studies investigating the role of both maternal and paternal correlates of parental overprotection.

It is possible that one parent's (in)secure attachment representations and feelings of separation anxiety do not only have an effect on the parent's own feelings and behaviors (actor-effect) but also on feelings and behaviors of the other parent (partner-effect). Previous studies on, for example, coping in couples found empirical evidence for such carry-over effects (e.g., Peterson et al. 2008). An Actor Partner Interdependence Model (APIM; Kenny et al. 2006) allows for the simultaneous estimation of both these actoras well as partner-effects. More specifically, APIM can be used to investigate whether one parent's attachment representations relates to the other parent's separation anxiety, above and beyond the parent's own attachment representations. An accumulating body of research also uses the APIM to examine dynamics in the parent-child relationship (e.g., Laursen et al. 2015). For example, research on attachment and conflict styles in adult child-parent relationships found empirical evidence for carry-over effects between parents and children (e.g., La Valley and Guerrero 2012).

Finally, it can be expected that separation anxiety and overprotectiveness would not only relate to more maladaptive parenting behaviors, but also to more negative affect in parents. A high degree of separation anxiety may pose a risk to feel emotionally bad in general, as associations were found between maternal separation anxiety and negative self-representations, low self-esteem and depressive symptomatology (Hock and Schirtzinger 1992; Hock et al. 1992; McBride and Belsky 1988). Further, previous research also found some support that parental separation anxiety might be associated with negative affect specifically linked to the matter of parent-child separation. Specifically, Wuyts et al. (2017) found that parents high on separation anxiety experience more tension during a conversation with their adolescent about the topic of peer relations and friendships, which is a topic that might constitute a threat to the parent-child relationship for separation-anxious parents.

The present research has two central research aims (see Fig. 1). The first aim of the present study was to investigate parental correlates of maternal and paternal overprotection, specifically during emerging adulthood. Using an APIM, we investigated both actor-effects and partner-effects when examining the link between attachment (distinguishing between attachment anxiety and avoidance), separation anxiety and perceived parental overprotection. The second aim of the present study was to investigate the link between the maternal variables central in Aim 1 and (a) maternal negative affect regarding home-leaving and (b) emerging adults' actual living situation. As fathers were not contacted at Wave 2 (due to practical considerations and based on previous research showing that fathers are more difficult to recruit, see Currie et al. 2016), only data regarding maternal feelings and behaviors were used for this second aim. We expected that mothers scoring higher on anxious attachment, separation anxiety, and overprotection would report 


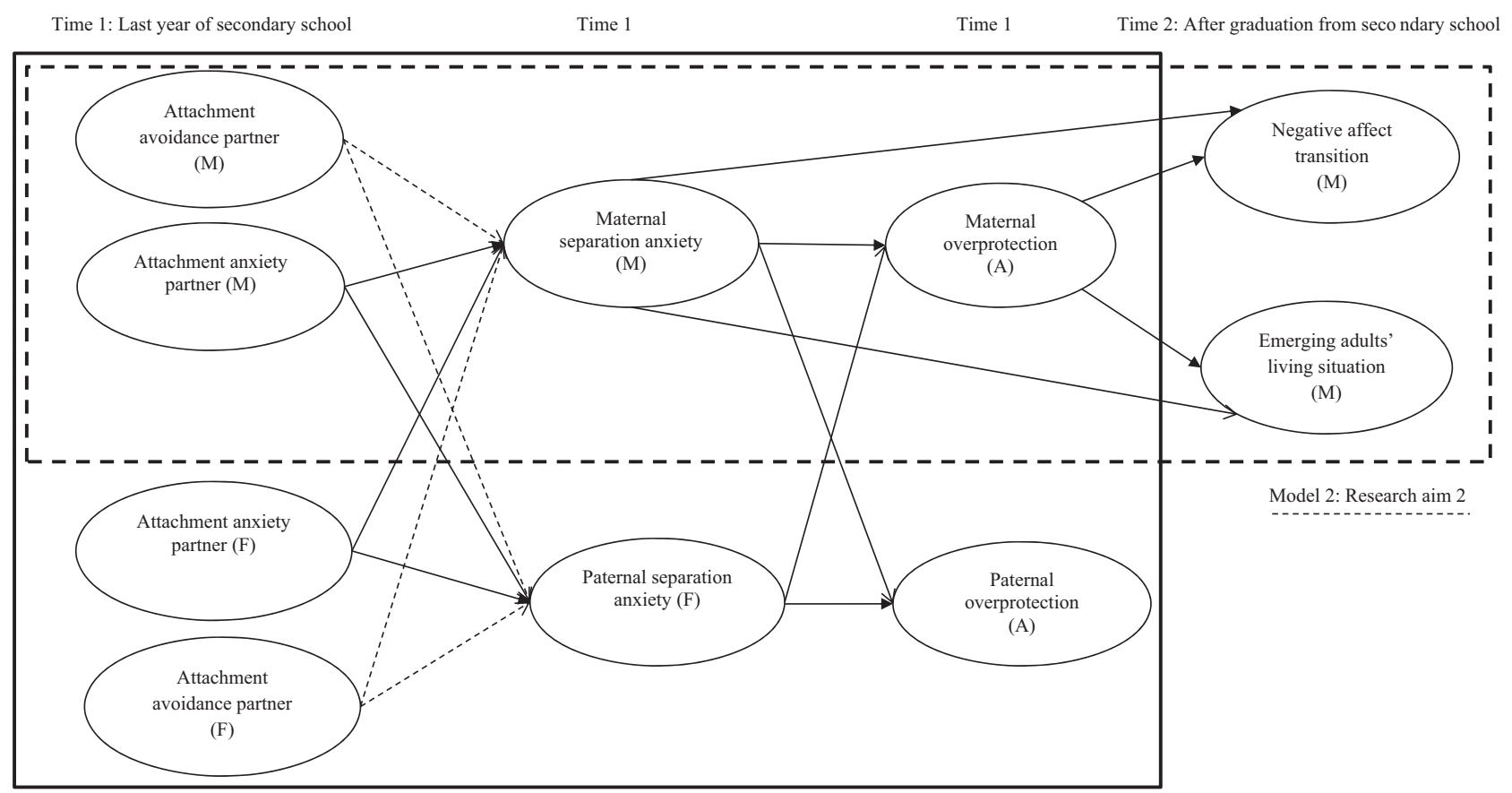

Model 1: Research aim 1

Fig. 1 Conceptual model. $\mathrm{M}=$ Mother report; $\mathrm{F}=$ Father report; $\mathrm{A}=$ Adolescent report

more negative affect because the transition after secondary school and the (imminent or actual) process of homeleaving is experienced as a threat to the parent-child bond. We also expected that children of overprotective mothers would be more likely to still live at home because these mothers would be inclined to discourage their child to leave the parental home.

\section{Method}

\section{Participants}

The sample of this study consists of 246 Dutch-speaking Caucasian families of which 246 adolescents (100\%), 242 mothers $(98.37 \%)$ and 218 fathers $(88.62 \%)$ participated. All adolescents (62.6\% female), with a mean age at Time 1 of 17.14 years (ranging between 16 and 20 years; $\mathrm{SD}=$ 0.66), lived at home at Wave 1. Regarding level of education, $65.9 \%$ were following an academic track (i.e., preparing for college or university studies), whereas the remaining participants were preparing for technical proficiencies. Regarding birth order, 26 adolescents (10.6\%) were an only child, 110 adolescents $(44.7 \%)$ were the youngest, $45(18.3 \%)$ situated themselves in the middle and 65 adolescents $(26.4 \%)$ were the oldest child in the family. The mothers had a mean age of $46.90(\mathrm{SD}=3.69)$, with a range between 32 and 58 years. Regarding maternal educational level, $3.7 \%$ of the mothers completed primary school as highest degree, $26.3 \%$ of the mothers completed secondary school, $54.2 \%$ had a bachelor's degree diploma, and $15.8 \%$ attained a master's degree diploma. The fathers had a mean age of $48.74(\mathrm{SD}=4.06)$, with a range between 40 and 69 years. Regarding educational level, $8.8 \%$ of the fathers completed primary school, $31.5 \%$ of the fathers completed secondary school, $36.6 \%$ had a bachelor's degree diploma, and $23.1 \%$ attained a master's degree diploma. As for family status, 196 families were intact (79.7\%). In these families, we obtained participation from both mother and father in most cases $(93.88 \%$, with the exception of 10 mother-only-respondents and 2 father-only-respondents). The remaining families were non-intact $(N=50)$, that is, divorced families $(17.5 \%)$ or families where one of the parents is deceased (2.8\%). In these non-intact families, the participating parents were already in a new relationship. As one of the key study variables was to investigate attachment representations about the current partner, only families in which parents were in a relationship were recruited. In other words, this study included no single-parent households. For non-intact families, we obtained participation from both partners in the majority of families (29 families), followed by 19 mother-only-respondents and two (non-intact) families in which only fathers responded.

At Wave 2 (1 year later, after graduation from secondary school), 137 mothers (55.69\%) participated again. With regard to the incomplete data of Wave 1 and Wave 2, all 
participants with and without complete data were compared using Little (1988) Missing Completely At Random test, which indicated that data were likely missing at random $\left(\chi^{2}(96)=108.37, n s\right)$. Based on this result, cases with missing values were included in the analyses using fullinformation maximum likelihood estimation (Little and Rubin 1987).

\section{Procedure}

Data of Wave 1 from this two-wave longitudinal study were gathered in the context of a course on developmental psychology. Undergraduate students were asked to invite two adolescents who were in their final year of secondary school to participate in this study, as well as their mother and/or father. The participating families, who all lived in the Dutch-speaking part of Belgium, were visited at home in order to hand them a set of paper-and-pencil questionnaires. This was done after having obtained active informed consent from all parties. Participation in the study was voluntary and confidentiality was guaranteed. All participants were assigned a unique code to ensure confidential treatment of the data. About 1 year later (with a maximum range of 2 month), all mothers were invited by phone to participate again in the study. Ethical approval for this study was granted by the organizing university's Institutional Review Board.

\section{Measures}

\section{Attachment representations (Time 1, mother and father report)}

A short version of the Experiences in Close Relationships Scale-Revised (Fraley et al. 2000) was used to measure maternal and paternal anxious and avoidant attachment. More specifically, mothers and fathers were asked to rate the 12 attachment statements about their current partner. The anxiety scale (6 items) taps into feelings of fear of abandonment and strong desires for interpersonal merger (e.g., "I worry about being abandoned by my partner"). The avoidance scale (6 items) assesses discomfort with closeness, dependence, and intimate self-disclosure (e.g., "I prefer not to show my partner how I feel deep down"). Items were rated on a 7-point scale ranging from "not at all" to "very much". The reliability and validity of the anxious and avoidant attachment scale are well-documented (e.g., Sibley et al. 2005; Sibley and Liu 2004). In this study, Cronbach alphas for mothers were .78 and .89 for attachment anxiety and avoidance, respectively. Cronbach alphas for fathers were .86 both for attachment anxiety and avoidance.
Separation anxiety (Time 1, mother and father report)

Maternal and paternal separation anxiety were measured using the Anxiety about Distancing (AAD) scale of the Parents of Adolescents Separation Anxiety Scale (Hock et al. 2001). The AAD scale counts 21 items and measures parents' negative emotions experienced in response to their children's increasing independence and imminent leavetaking (e.g., " I feel sad when I realize my teenager no longer likes to do the things that we used to enjoy doing together."). Items are rated on a 5-point scale ranging from 1 (not at all) to 5 (very much). Reliability and validity of the AAD is well documented (Hock et al. 2001). In this study, Cronbach alphas were .89 and .92 for maternal and paternal separation anxiety, respectively.

\section{Overprotection (Time 1, adolescent report)}

Perceived overprotection was measured using the six parental anxious overprotectiveness subscales of the Multidimensional Overprotective Parenting Scale (Kins and Soenens 2013). Each of the subscales count 5 items, resulting in 30 items in total, representing six components of anxious overprotection: anxious rearing (e.g., "My mother / father shows me the possible risks in everything I do"), premature problem solving (e.g., "My mother / father has been trying to solve my own problems without me doing anything"), babying (e.g., "My mother / father is treating me in a childish way"), privacy invasion (e.g., "My mother / father violates my privacy"), hyperactivation of emotions (e.g., "When something happens to me, it seems my mother / father is more upset than I am"), and general items on parental overprotection (e.g., "My mother/father is overprotective"). Previous research revealed good psychometric properties (Kins and Soenens 2013). Cronbach alpha in the present study was .91 for adolescent report on both perceived maternal and paternal overprotection.

Maternal negative affect regarding the adolescent's homeleaving (Time 2, mother report)

At Time 2, mothers reported upon how they would feel (or actually felt) about their child's home-leaving. An adapted version of the Negative Affect Schedule (Watson et al. 1988) was used to tap into maternal negative feelings. Thereby, mothers filled out six items tapping into negative feelings when thinking about the time when their emerging adult will be (or was) leaving the parental home. Specifically, the following instructions were given to all mothers: "When you think (or think back) at the moment your son/ daughter will leave (or has left) the parental home...". Six negative emotions are specified and adapted to focus specifically on the parent-child separation (e.g., "..., I feel sad 
Table 1 Means, standard deviations, and correlations among study variables

\begin{tabular}{|c|c|c|c|c|c|c|c|c|c|c|}
\hline Variable & $\operatorname{Ax}(M)$ & $\operatorname{Av}(M)$ & $\mathrm{SA}(\mathrm{M})$ & $\mathrm{OPm}(\mathrm{A})$ & $\operatorname{Ax}(F)$ & $\operatorname{Av}(F)$ & $\mathrm{SA}(\mathrm{F})$ & $\operatorname{OPf}(\mathrm{A})$ & LS & NA $(\mathrm{M})$ \\
\hline Anxious attachment (M) & - & & & & & & & & & \\
\hline Avoidant attachment (M) & $.42 * * *$ & _ & & & & & & & & \\
\hline Separation anxiety (M) & $.29 * * *$ & .10 & _- & & & & & & & \\
\hline Overprotection mother (A) & .09 & -.08 & $.32 * * *$ & - & & & & & & \\
\hline Anxious attachment $(\mathrm{F})$ & $.27 * * *$ & $.30 * * *$ & $.13^{\dagger}$ & -.04 & - & & & & & \\
\hline Avoidant attachment $(\mathrm{F})$ & $.30 * * *$ & $.35 * * *$ & .08 & .01 & $.49 * * *$ & - & & & & \\
\hline Separation anxiety $(F)$ & $.23 * *$ & $.12^{\dagger}$ & $.37 * * *$ & $.25 * * *$ & $.32 * * *$ & $.18 * *$ & - & & & \\
\hline Overprotection father (A) & $.14^{*}$ & -.08 & $.18^{* *}$ & $.51 * * *$ & .01 & $-.17 *$ & $.26 * * *$ & - & & \\
\hline $\begin{array}{l}\text { Living situation (1-2; home } \\
\text { or not) }\end{array}$ & -.05 & .02 & $-.20 *$ & $-.27 * *$ & -.04 & .03 & $-.25^{* *}$ & $-.30 * * *$ & - & \\
\hline $\begin{array}{l}\text { Negative affect transition } \\
\text { (M) }\end{array}$ & .01 & .05 & $.58 * * *$ & $.35^{* * *}$ & .06 & .10 & $.22 *$ & $.27 * *$ & $-.20 *$ & - \\
\hline Mean & 2.44 & 2.55 & 2.50 & 15.29 & 2.43 & 2.60 & 2.37 & 13.64 & 1.42 & 5.11 \\
\hline Standard Deviation & 0.97 & 1.09 & 0.51 & 3.21 & 1.11 & 1.06 & 0.51 & 3.04 & 0.50 & 1.24 \\
\hline
\end{tabular}

$M$ mother report, $F$ father report, $A$ adolescent report

${ }^{\dagger} p<.10, * p<.05, * * p<.01, * * * p<.001$

because I will miss him/her"). A Likert scale, ranging from 1 (completely not true) to 5 (completely true), was used for this questionnaire. Chronbach alpha in the present study was .75 .

\section{Adolescents' living situation (Time 2, mother report)}

At wave 2, a single item measure was used to assess the emerging adults' living situation. The item reads: "My son/ daughter is: living at home (item score $=1$ ) / living away from home (e.g., in a student's flat, item score $=2$ )".

\section{Data Analyses}

Before examining the two central research questions, we tested for the role of several relevant background variables by performing a MANCOVA, with age and number of children as covariates and with gender, family structure and place in the birth order (youngest, oldest, in between) as fixed factors, and with the variables of interest as dependent variables. To examine our first research question (i.e., investigating parental correlates of both maternal and paternal overprotection) using APIM (see Fig. 1: Model 1), we conducted Structural Equation Modeling (SEM) using MPlus (Muthén and Muthén 2012). Specifically, we investigated the link between parental attachment representations, separation anxiety and perceived overprotection. To investigate our second research question we also used SEM but now including both Wave 1 and 2 and only relying on data regarding the mother-child relationship (see Fig. 1: Model 2). Specifically, we investigated the link between maternal separation anxiety, perceived maternal overprotection and two outcomes variables, that is, maternal negative affect regarding home-leaving and the emerging adult's living situation. We evaluated model fit (both for research aim 1 and 2) based on a combined consideration of the Chi-square statistic $\left(\chi^{2}\right)$, the Comparative Fit Index (CFI), the Root Mean Square Error of Approximation (RMSEA) and the Standardized Root-Mean-square Residual (SRMR). The $\chi^{2}$ should be as small as possible. A CFI value of .90 or higher indicates a reasonable fit, whereas an RMSEA value of .06 or lower and a SRMR value of .08 or lower indicate acceptable fit (Kline 2010).

\section{Results}

Correlations among the study variables are presented in Table 1. As expected, both in mothers and fathers, attachment anxiety correlated positively with parental separation anxiety. Parental avoidant attachment only correlated significantly positively with separation anxiety in fathers. Further, maternal and paternal separation anxiety correlated positively with both maternal and paternal overprotection (as reported by the adolescent). The correlation between anxious and avoidant attachment and overprotection was non-significant in mothers. In fathers, the association between anxious attachment and overprotection was nonsignificant, whereas the association between paternal avoidant attachment and paternal overprotection was negative. The second part of Table 1 shows correlations among the study variables of wave 1 and two maternal outcome variables as measured on wave 2. Maternal separation anxiety and overprotection significantly correlated with both 
Fig. 2 APIM model

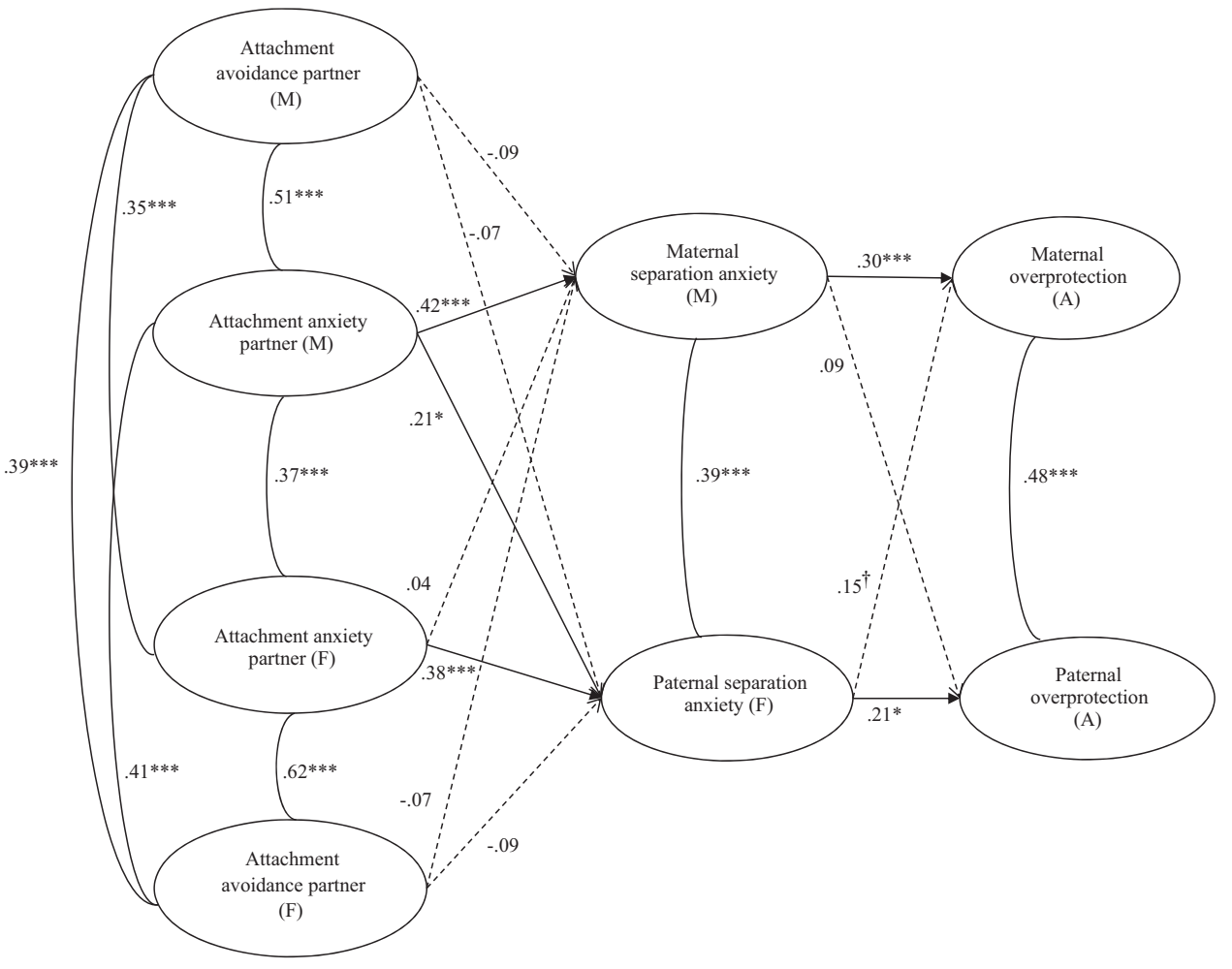

outcome variables, that is, maternal negative affect with regard to adolescent home-leaving and the actual living situation of the emerging adult, with higher scores on maternal separation anxiety and overprotection being related to a higher likelihood that the emerging adult still lived at home. Table 1 also presents the means and standard deviations of all study variables.

Next, we examined differences in the study variables in terms of age (adolescent, mother and father), adolescents' gender, family structure, number of children and the adolescents' place in the birth order. No significant multivariate effects were obtained for age (Wilk's Lambda $=.88 ; F(10$, $82)=1.11, p>.05 ;$ Wilk's Lambda $=.88 ; F(10,82)=$ $1.09, p>.05 ;$ Wilk's Lambda $=.87 ; F(10,82)=1.20, p$ $>.05$, for adolescents', mother's and father's age, respectively), for adolescents' gender (Wilk's Lambda $=.84 ; F$ $(10,82)=1.60, p>.05)$, family structure (Wilk's Lambda $=.79 ; F(20,164)=1.02, p>.05)$, number of children $($ Wilk's Lambda $=.92 ; F(10,82)=0.67, p>.05)$ nor place in birth order (Wilk's Lambda $=.74 ; F(30,241)=0.89, p$ $>.05)$. Further, none of the two- or three-way interactions between the background variables had a significant effect $(p>.05)$.

In a following step, we conducted SEM with latent variables. A first step was to inspect the measurement model. To model the nine latent variables in the measurement model (maternal as well as paternal attachment anxiety and avoidance, maternal and paternal separation anxiety, maternal and paternal overprotection as reported by the adolescent, and maternal negative affect regarding homeleaving), we made use of parceling. The parcels for attachment and separation anxiety each consisted of a set of three randomly selected items. Further, there were six parcels for perceived maternal and paternal overprotection, each consisting of a subscale of the anxious overprotection questionnaire. Finally, there were six parcels for maternal negative effect consisted of the six items of the scale. The measurement model $\quad\left(\chi^{2}(552)=858.56 ; \quad \mathrm{CFI}=.93\right.$; $\mathrm{RMSEA}=.05 ; \mathrm{SRMR}=.06)$ had 36 indicators with significant $(p<.001)$ and moderate to strong loadings on the eight latent factors, ranging from .37 to .96 (mean $\lambda=.75$ ).

Figure 2 (APIM model) provides a visual depiction of our first model including actor and partner effects between parental attachment representations, separation anxiety and the association with perceived maternal and paternal overprotection. The structural model showed good model fit $\left(\chi^{2}(379)=633.70 ; \quad \mathrm{CFI}=.94 ; \quad \mathrm{RMSEA}=.05 ; \quad\right.$ SRMR $=.07)$. For maternal attachment anxiety, there was a significant actor effect with maternal separation anxiety, indicating that mothers with more anxious attachment representations (towards their partner) also experience more separation anxiety (towards their child). Further, for paternal attachment anxiety, there was both a significant actor effect and a partner effect with paternal separation anxiety. The actor effect indicates that fathers with more anxious attachment representations (towards their partner) also 
Fig. 3 Prospective model

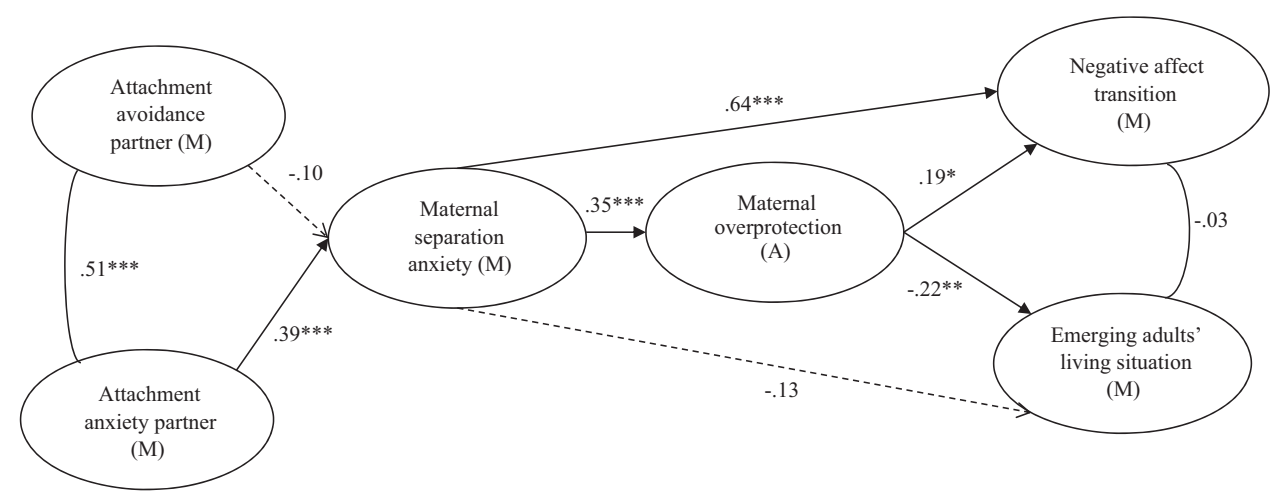

experience more separation anxiety (towards their child), and the partner effect indicates that anxious attachment in mothers also relates to more separation anxiety in fathers. For attachment avoidance, there were no significant actor nor partner effects on parental separation anxiety. For maternal and paternal separation anxiety, there were significant actor effects with maternal and paternal overprotection respectively, indicating that parents with more separation anxiety also show more parental overprotection as perceived by their adolescent child. Finally, there was one marginally significant partner effect between paternal separation anxiety and maternal overprotection.

Figure 3 (Prospective model) provides a visual depiction of our second model investigating the link between maternal attachment representations, maternal separation anxiety, maternal overprotection, and the relation with emerging adults' living situation and maternal negative effect regarding adolescent home-leaving. The structural model showed good model fit $\left(\chi^{2}(201)=310.10 ; \quad\right.$ CFI $=.95$; $\mathrm{RMSEA}=.05 ; \mathrm{SRMR}=.07)$. Maternal separation anxiety was linked with more maternal negative affect regarding home-leaving both directly, and indirectly via perceived maternal overprotection. Further, maternal overprotection was significantly linked to the emerging adults' living situation. Specifically, higher scores on perceived overprotection were related to a greater likelihood of living at home.

As the link between Time 1 maternal separation anxiety, perceived overprotection and Time 2 maternal negative affect regarding home-leaving could be different for emerging adults with a different actual living situation at Time 2 (i.e., moderation by living situation), a multigroup analysis was conducted comparing a constrained model (in which the loadings were set to be invariant across parents whose adolescents did or did not leave the parental home) with an unconstrained model (in which these parameters were freely estimated across groups). Possibly, depending on the homeleaving experience they went through, maternal separation anxiety could be more (or less) strongly associated with maternal negative affect regarding home-leaving. We examined the difference in chi-square $\left(\Delta \chi^{2}\right)$, the Comparative Fit Index $(\triangle \mathrm{CFI})$ and the Non-Normed Fit Index ( $\triangle \mathrm{NNFI}$ ) to compare the models. We assumed equivalence when two of the three following criteria were met (Cheung and Rensvold 2002; Vandenberg and Lance 2000): a nonsignificant difference in Chi-square, a difference in CFI lower than .01 and a difference in NNFI lower than .02. All three criteria were met $\left(\Delta \chi^{2}(6)=7.25, p>.05 ; \Delta \mathrm{CFI}<.01\right.$; $\triangle \mathrm{NNFI}<.02)$, which indicates that there are no significant differences between the structural models for mothers of adolescents who did vs. who did not leave the parental home.

\section{Discussion}

The present study had two central research aims, that is, (a) investigating parental attachment representations and parental separation anxiety as possible correlates of perceived overprotective parenting, and (b) investigating mother's own experiences regarding child's home-leaving as well as the actual living situation of the emerging adult as two important correlates of maternal separation anxiety and overprotection. The strengths of this study were four-fold. First, this study investigates an interesting and innovative research question focusing on parental characteristics that could explain why some parents are more overprotective than others during emerging adulthood. Second, the present study included both mothers and fathers using an Actor Partner Interdependence Model. Third, whereas previous research typically investigated the implications of overprotective parenting for adolescent well-being (see Segrin et al. 2015), this study examined relations with the parents' experiences, as we investigated the mothers' negative affect associated with the home-leaving process. Finally, in addition to investigating parental negative affect regarding adolescent home-leaving, the present study included an objective behavioral outcome, that is, the emerging adult's living situation. 
The first aim of this study was to investigate the parental correlates of perceived overprotective parenting in emerging adulthood, an age period during which parental overprotection might hamper emerging adults' successful resolution of a number of developmental goals. Consistent with previous research (Cooklin et al. 2013; Mayseless and Scher 2000), the results suggest that parents' anxious attachment representations were associated with more separation anxiety, which in turn related to more perceived parental overprotection. Further, an APIM approach allowed us to investigate whether there were also partner effects in the link between attachment, separation anxiety and overprotection. We found evidence for one significant and one marginally significant partner effect. That is, mothers' anxious attachment not only related to their own feelings of separation anxiety but also predicted more paternal separation anxiety towards the child. Further, fathers' separation anxiety not only related to perceived paternal overprotection but also predicted more maternal overprotection (albeit only marginally so). According to the family system theory (Cox and Paley 1997), the existence of partner influences may suggest that the quality of interparental relationships also matter when considering the fathers' and mothers' use of parenting techniques. Further, the present study results are in accordance with the spillover hypothesis (e.g., Erel and Burman 1995) which assumes that individuals' functioning in one subsystem (e.g., parental relationship) has an impact on individuals' functioning in another subsystem (e.g., parent-child relationship). Specifically, the current results seem to suggest that the quality of the parental relationship (i.e., which is characterized here by jealousy and fear and vigilance concerning abandonment and rejection) may spill over and affect the parent-child relationship. Particularly, when interacting with their child, fathers may be affected by the anxious feelings, behaviors and cognitions of mothers as shown in the parental relationship.

A second aim of the current study was to investigate mothers' own experiences of their child's home-leaving as a correlate of maternal separation anxiety and overprotection. The present study found support that maternal separation anxiety (which may be seen as a direct manifestation of parental attachment anxiety) is directly related to more maternal negative affect regarding home-leaving. This association is in line with the assumptions of attachment theory (Bowlby 1973, 1980) as anxiously attached mothers are expected to perceive mother-child separation as threatening and stressful. Note that the strength of this association was quite strong in the present study $(\beta=.64, p$ $<.001)$. However, this was not totally unexpected, as previous research investigating the link between maternal separation anxiety and experienced tension regarding an adult child-parent conversation about friendship already yielded a correlation of $.34(p<.01)$ (Wuyts et al. 2017). If talking about the topic of peer relations already constitutes a threat and a source of stress for parents high on separation anxiety, it makes sense that the process of leaving the parental home is even more stressful and threatening to parents high on separation anxiety. Further, maternal separation anxiety is also indirectly related to maternal negative affect regarding home-leaving through maternal overprotection. In line with previous preliminary findings (see Wuyts et al. 2017), it seems that maternal overprotection does not only lead to negative consequences for who is receiving it (e.g., emerging adult) but also for who is displaying it (i.e., the mother herself). An interesting avenue for future research is to examine associations between maternal separation anxiety, maternal overprotection and more general outcomes of maternal mental health (e.g., maternal depressive symptoms, see Hock and Schirtzinger 1992). Further, although maternal separation anxiety and overprotection may play an important role as predictors of maternal well-being (especially during specific phases in life such as the empty nest phase), maternal mental health status may also have an influence on maternal parenting behaviors (e.g., Gustafsson et al. 2012). As such, future longitudinal research is needed to investigate this issue.

Finally, the present study found support for a link between maternal overprotection and the actual living situation of the emerging adult 1 year later. Specifically, more maternal overprotection predicted a higher likelihood of the emerging adult still living at home. For anxiously attached parents, overprotection seems to provide an "adaptive" strategy to temporarily postpone the impending separation and thus to deactivate the attachment system (Hock et al. 2001). However, for the emerging adult (taking into account their developmental tasks, e.g., reorganization of the living situation), prolonged staying at home driven by parental overprotection may form a challenge (see Kins et al. 2014). Research has indeed shown that emerging adults who feel pressured to stay at home display lower well-being compared to those who freely choose to stay home (Kins et al. 2009). Under overprotective and pressuring conditions, daily parental monitoring might for example limit emerging adults' exploration of possibilities in a variety of domains (e.g., love, work, and worldviews).

\section{Limitations and Directions for Future Research}

Although this study contributed to a greater understanding of parental factors related to overprotective parenting in emerging adulthood, some limitations are worthy of discussion. First, as the current study relied mainly on a crosssectional measurement of the parental variables, our findings do not provide a sufficient base for inferring direction of effects. As such, future research should provide a specific 
test on the direction of effects in associations between parental attachment, separation anxiety and overprotection. Although anxious attachment representations and separation anxiety are expected to induce more overprotective parenting (George and Solomon 2008), parental overprotection could also trigger feelings of reactance and rejection and, ironically, might push the emerging adult away from the parents, thereby reinforcing the parents' anxious attachment representations. Further, while parental factors (e.g., attachment representations and separation anxiety) shape parenting behaviors (e.g., overprotection), the mother-child relationship is transactional as parenting also responds to children's behavior. As such, it may be that adolescents who demonstrate frequent or intensive difficult behaviors (e.g., children who are less predictable, more reactive and less able to self-regulate) elicit more concern, worry, and protective behaviors in their parents (Cooklin et al. 2013). As such, future research is needed to disentangle these dynamics.

Second, it should be noted that our sample generally consisted of well-adjusted Dutch-speaking Caucasian families. This sets limitations to the generalizability of the findings. Future research relying on more heterogeneous samples (in terms of ethnicity, socio-economic status, and family structure) is needed to further test the validity of the model proposed here. Further, as the present study only included maternal data at Wave 2 with a significant amount of drop-out, future research should invest in the recruitment and follow-up of all relevant parties (including fathers).

Third, although the current study provides new insights in the role of several parental factors related to overprotective parenting, future research should also incorporate other parental factors (e.g., parents' personality), child factors (e.g., emerging adult's relationship status) and environmental factors. Regarding the influence of environmental factors, recent research applying a broader socioecological perspective has found associations between high separation anxiety (postpartum) and social adversity (including financial hardship, residing in a poor quality neighborhood, and receiving inadequate social support) (Cooklin et al. 2013). This suggests that high maternal separation anxiety might also be a response to environmental circumstances rather than being fully determined by personal factors (e.g., attachment representations). Regarding child factors, children's difficult behaviors may elicit certain parenting behaviors (as outlined above), but child factors (such as child temperament and child health problems) may also explain why two variables are related. For example, regarding the link between overprotection and the emerging adult's actual living situation, caution is needed in drawing firm conclusions. Possibly, the link between perceived overprotection and living situation is caused by third variables such as temperament. Further, children's own attachment representations could be investigated as an important child factor.

Funding This study was funded by Research Foundation-Flanders (grant number FWO.3EO.2015.0012.01).

Authors' Contributions K.B. designed and executed the study, performed the data analyses, and wrote the paper. B.S. collaborated with the design, data analyses and writing of the study. S.V.P. collaborated with the writing of the manuscript and editing of the final manuscript. E.K. collaborated with the design and execution of the study.

\section{Compliance with Ethical Standards}

Conflict of Interest The authors report that they have no competing interests.

Ethical Approval All procedures performed involving human participants in this study were in accordance with the ethical standards of the $* * * * *$ (blinded for review) University Institutional Review Board and with the 1964 Helsinki declaration and its later amendments or comparable ethical standards.

Informed Consent Informed consents were obtained from all participants included in the study.

\section{References}

Adam, E. K., Gunnar, M. R., \& Tanaka, A. (2004). Adult attachment, parent emotion, and observed parenting behavior: Mediator and moderator models. Child Development, 75, 110-122. doi:10. 1111/j.1467-8624.2004.00657.x.

Arnett, J. J. (1998). Learning to stand alone: The contemporary American transition to adulthood in cultural and historical context. Human Development, 41, 295-315. doi:10.1159/ 000022591.

Arnett, J. J. (2001). Conceptions of the transition to adulthood: Perspectives from adolescence through midlife. Journal of Adult Development, 8, 133-143. doi:10.1023/a:1026450103225.

Arnett, J. J. (2004). Emerging adulthood: The winding road from the late teens through the twenties. New York: Oxford University Press.

Bartle-Haring, S., Brucker, P., \& Hock, E. (2002). The impact of parental separation anxiety on identity development in late adolescence and early adulthood. Journal of Adolescent Research, 17, 439-450. doi:10.1177/0743558402175001.

Bouchard, G. (2014). How do parents react when their children leave home? An integrative review. Journal of Adult Development, 21, 69-79. doi:10.1007/s10804-013-9180-8.

Bowlby, J. (1973). Attachment and loss: Vol. 2. Separation and anxiety. New York: Basic Books.

Bowlby, J. (1980). Attachment and loss: Vol 3. Sadness and depression. New York: Basic Books.

Brennan, K. A., Clark, C. L., \& Shaver, P. R. (1998). Self-report measurement of adult romantic attachment: An integrative overview. In J. A. Simpson, \& W. S. Rholes (Eds.), Attachment theory and close relationships (pp. 46-76). New York: The Guilford Press.

Cheung, G. W., \& Rensvold, R. B. (2002). Evaluating goodness-of-fit indexes for testing measurement invariance. Structural Equation Modeling, 9, 233-255. doi:10.1207/s15328007sem0902_5. 
Cooklin, A. R., Giallo, R., D'Esposito, F., Crawford, S., \& Nicholson, J. M. (2013). Postpartum maternal separation anxiety, overprotective parenting, and children's social-emotional well-being: Longitudinal evidence from an Australian cohort. Journal of Family Psychology, 27, 618-628. doi:10.1037/a0033332.

Cox, M. J., \& Paley, B. (1997). Families as systems. Annual Review of Psychology, 48, 243-267. doi:10.1146/annurev.psych.48.1.243.

Currie, E. R., Roche, C., Christian, B. J., Bakitas, M., \& Meneses, K. (2016). Recruiting bereaved parents for research after infant death in the neonatal intensive care unit. Applied Nursing Research, 32, 281-285. doi:10.1016/j.apnr.2016.08.012.

Erel, O., \& Burman, B. (1995). Interrelatedness of marital relations and parent-child relations: A meta-analytic review. Psychological Bulletin, 118, 108-132. doi: 10.1037//0033-2909.118.1.108.

Erickson, J. J., Martinengo, G., \& Hill, E. J. (2010). Putting work and family experiences in context: Differences by family life stage. Human Relations, 63, 955-979. doi:10.1177/0018726709353138.

Fraley, R. C., \& Spieker, S. J. (2003). Are infant attachment patterns continuously or categorically distributed? A taxometric analysis of strange situation behavior. Developmental Psychology, 39, 387-404. doi:10.1037/0012-1649.39.3.387.

Fraley, R. C., Waller, N. G., \& Brennan, K. A. (2000). An item response theory analysis of self-report measures of adult attachment. Journal of Personality and Social Psychology, 78, 350-365. doi: 10.1037//0022-3514.78.2.350.

Garcia-Ruiz, M., Rodrigo, M. J., Hernandez-Cabrera, J. A., \& Maiquez, M. L. (2013). Contribution of parents' adult attachment and separation attitudes to parent-adolescent conflict resolution. Scandinavian Journal of Psychology, 54, 459-467. doi:10.1111/ sjop.12077.

George, C., \& Solomon, J. (2008). The caregiving system: A behavioral approach to parenting. In J. Cassidy, \& P. R. Shaver (Eds.), Handbook of attachment. New York: Guilford Press.

Gustafsson, H. C., \& Cox, M. J. (2012). Relations among intimate partner violence, maternal depressive symptoms, and maternal parenting behaviors. Journal of Marriage and Family, 74, 1005-1020. doi:10.1111/j.1741-3737.2012.01010.x.

Hock, E., Eberly, M., Bartle-Haring, S., Ellwanger, P., \& Widaman, K. F. (2001). Separation anxiety in parents of adolescents: Theoretical significance and scale development. Child Development, 72, 284-298. doi:10.1111/1467-8624.00279.

Hock, E., \& Schirtzinger, M. B. (1992). Maternal separation anxiety: Its developmental course and relation to maternal mental-health. Child Development, 63, 93-102. doi:10.1111/j.1467-8624.1992. tb03598.x.

Hock, E., Schirtzinger, M. B., \& Lutz, W. (1992). Dimensions of family relationships associated with depressive symptomatology in mothers of young children. Psychology of Women Quarterly, 16, 229-241. doi:10.1111/j.1471-6402.1992.tb00252.x.

Holmbeck, G. N., Johnson, S. Z., Wills, K. E., McKernon, W., Rose, B., Erklin, S., \& Kemper, T. (2002). Observed and perceived parental overprotection in relation to psychosocial adjustment in preadolescents with a physical disability: The mediational role of behavioral autonomy. Journal of Consulting and Clinical Psychology, 70, 96-110. doi: 10.1037//0022-006x.70.1.96.

Kenny, D. A., Kashy, D. A., \& Cook, W. L. (2006). Dyadic Data Analysis. New York: The Guilford Press.

Kins, E., Beyers, W., Soenens, B., \& Vansteenkiste, M. (2009). Patterns of home leaving and subjective well-being in emerging adulthood: The role of motivational processes and parental autonomy support. Developmental Psychology, 45, 1416-1429. doi:10.1037/a0015580.

Kins, E., De Mol, J., \& Beyers, W. (2014). "Why should i leave?" Belgian emerging adults' departure from home. Journal of Adolescent Research, 29, 89-119. doi:10.1177/0743558413508201.
Kins, E., \& Soenens, B. (2013). Generation me and its helicopter parents. Paper presented at the 16th European Conference on Developmental Psychology, Lausanne, Switzerland.

Kins, E., Soenens, B., \& Beyers, W. (2011). "Why do they have to grow up so fast?" Parental separation anxiety and emerging adults' pathology of separation-individuation. Journal of Clinical Psychology, 67, 647-664. doi:10.1002/jclp.20786.

Kline, R. B. (2010). Principles and practice of Structural Equation Modeling (3 ed.). New York: Guilford Press.

Kobak, R., Ferenzgillies, R., Everhart, E., \& Seabrook, L. (1994). Maternal attachment strategies and emotion regulation with adolescent offspring. Journal of Research on Adolescence, 4, 553-566. doi:10.1207/s15327795jra0404_7.

Koepke, S., \& Denissen, J. J. A. (2012). Dynamics of identity development and separation-individuation in parent-child relationships during adolescence and emerging adulthood - A conceptual integration. Developmental Review, 32, 67-88. doi:10. 1016/j.dr.2012.01.001.

Laursen, B., Zukauskiene, R., Raiziene, S., Hiatt, C., \& Dickson, D. J. (2015). Perceived parental protectiveness promotes positive friend influence. Infant and Child Development, 24, 452-468. doi:10.1002/icd.1885.

La Valley, A. G., \& Guerrero, L. K. (2012). Perceptions of conflict behavior and relational satisfaction in adult parent-child relationships: A Dyadic analysis from an attachment perspective. Communication Research, 39, 48-78. doi:10.1177/ 0093650210391655.

LeMoyne, T., \& Buchanan, T. (2011). Does "Hovering" matter? Helicopter parenting and its effect on well-being. Sociological Spectrum, 31, 399-418. doi:10.1080/02732173.2011.574038.

Little, R. J. A. (1988). A test of missing completely at random for multivariate data with missing values. Journal of the American Statistical Association, 83, 1198-1202. doi:10.2307/2290157.

Little, R. J. A., \& Rubin, D. B. (1987). Statistical analysis with missing data. New York: Wiley.

Lutz, W. J., \& Hock, E. (1995). Maternal separation anxiety: Relations to adult attachment representations in mothers of infants. Journal of Genetic Psychology, 156, 57-72.

Mayseless, O., \& Scher, A. (2000). Mother's attachment concerns regarding spouse and infant's temperament as modulators of maternal separation anxiety. Journal of child psychology and psychiatry, and allied disciplines, 41, 917-925. doi:10.1017/ s0021963099006113.

McBride, S., \& Belsky, J. (1988). Characteristics, determinants, and consequences of maternal separation anxiety. Developmental Psychology, 24, 407-414. doi:10.1037/0012-1649.24.3.407.

Muthén, L. K., \& Muthén, B. O. (2012). Mplus user's guide (Vol. 7). Los Angeles: CA: Muthén \& Muthén.

Padilla-Walker, L. M., \& Nelson, L. J. (2012). Black hawk down?: Establishing helicopter parenting as a distinct construct from other forms of parental control during emerging adulthood. Journal of Adolescence, 35, 1177-1190. doi:10.1016/j. adolescence.2012.03.007.

Parker, G. (1983). Parental overprotection: A risk factor in psychosocial development. New York: Grune \& Stratton.

Peterson, B. D., Pirritano, M., Christensen, U., \& Schmidt, L. (2008). The impact of partner coping in couples experiencing infertility. Human Reproduction, 23, 1128-1137. doi:10.1093/humrep/ den067.

Rousseau, S., \& Scharf, M. (2015). "I will guide you" The indirect link between overparenting and young adults' adjustment. Psychiatry Research, 228, 826-834. doi:10.1016/j.psychres.2015.05.016.

Scher, A., \& Hershkovitz, R. (1998). Maternal separation anxiety in infancy: Precursors and outcomes. Child Psychiatry \& Human Development, 29, 103-111. doi:10.1023/a:1025031931770. 
Schwartz, S. J. (2016). Turning point for a turning point: Advancing emerging adulthood theory and research. Emerging Adulthood, 4, 307-317.

Schwartz, S. J., Cote, J. E., \& Arnett, J. J. (2005). Identity and agency in emerging adulthood: Two development routes in the individualization process. Youth \& Society, 37, 201-229. doi:10.1177/ $0044118 x 05275965$.

Segrin, C., Givertz, M., Swaitkowski, P., \& Montgomery, N. (2015). Overparenting is associated with child problems and a critical family environment. Journal of Child and Family Studies, 24, 470-479. doi:10.1007/s10826-013-9858-3.

Segrin, C., Woszidlo, A., Givertz, M., \& Montgomery, N. (2013). Parent and child traits associated with overparenting. Journal of Social and Clinical Psychology, 32, 569-595.

Shaver, P. R., \& Mikulincer, M. (2002). Attachment-related psychodynamics. Attachment and Human Development, 4, 133-161.

Sibley, C. G., Fischer, R., \& Liu, J. H. (2005). Reliability and validity of the revised experiences in close relationships (ECR-R) selfreport measure of adult romantic attachment. Personality and Social Psychology Bulletin, 31, 1524-1536. doi:10.1177/ 0146167205276865.

Sibley, C. G., \& Liu, J. H. (2004). Short-term temporal stability and factor structure of the revised experiences in close relationships (ECR-R) measure of adult attachment. Personality and Individual Differences, 36, 969-975. doi: 10.1016/s0191-8869(03)00165-x.

Simpson, J. A., Rholes, W. S., \& Phillips, D. (1996). Conflict in close relationships: An attachment perspective. Journal of Personality and Social Psychology, 71, 899-914. doi:10.1037/0022-3514.71. 5.899 .

Soenens, B., Vansteenkiste, M., Duriez, B., \& Goossens, L. (2006). In search of the sources of psychologically controlling parenting: The role of parental separation anxiety and parental maladaptive perfectionism. Journal of Research on Adolescence, 16, 539-559. doi:10.1111/j.1532-7795.2006.00507.x.

Soenens, B., Vansteenkiste, M., \& Luyten, P. (2010). Toward a domain-specific approach to the study of parental psychological control: Distinguishing between dependency-oriented and achievement-oriented psychological control. Journal of Personality, 78, 217-256. doi:10.1111/j.1467-6494.2009.00614.x.

Thomasgard, M., Metz, W. P., Edelbrock, C., \& Shonkoff, J. P. (1995). Parent-child relationship disorders. Part 1: Parental overprotection and the development of the parent protection scale. Journal of Developmental and Behavioral Pediatrics, 16, 244-250.

Umberson, D., Williams, K., Powers, D. A., Chen, M. D., \& Campbell, A. M. (2005). As good as it gets? A life course perspective on marital quality. Social Forces, 84, 493-511. doi:10.1353/sof. 2005.0131.

Vandenberg, R. J., \& Lance, C. E. (2000). A review and synthesis of the measurement invariance literature: Suggestions, practices, and recommendations for organizational research. Organizational Research Methods, 3, 4-70.

Verschueren, K., Dossche, D., Marcoen, A., Mahieu, S., \& Bakermans-Kranenburg, M. (2006). Attachment representations and discipline in mothers of young school children: An observation study. Social Development, 15, 659-675. doi:10.1111/j.14679507.2006.00363.x.

Watson, D., Clark, L. A., \& Tellegen, A. (1988). Development and validation of brief measures of positive and negative affect: The PANAS scales. Journal of Personality and Social Psychology, 54, 1063-1070. doi:10.1037/0022-3514.54.6.1063.

Wuyts, D., Soenens, B., Vansteenkiste, M., Van Petegem, S., \& Brenning, K. (2017). (in press). The role of separation anxiety in mothers' use of autonomy support: An observational study. Journal of Child and Family Studies. doi:10.1007/s10826-0170707-7. 